\title{
Cation Dependant Carbonate Speciation and the Effect of Water
}

Greg A. Mutch ${ }^{1}$, Sara Morandi ${ }^{2,3}$, Rebecca Walker ${ }^{1}$, James A. Anderson ${ }^{1}$, David VegaMaza $^{1}$, Lorenza Operti ${ }^{2,3}$, Giuseppina Cerrato ${ }^{2,3^{*}}$

${ }^{1}$ Materials and Chemical Engineering Group, School of Engineering, Fraser Noble Building, King's College, University of Aberdeen, Aberdeen, AB24 3UE (UK).

${ }^{2}$ Department of Chemistry \& NIS Interdept. Centre, University of Torino, via P. Giuria, 7 10125 Torino (Italy).

${ }^{3}$ Consorzio INSTM, UdR Torino, via G. Giusti, 9 - 50121 Firenze (Italy).

*Corresponding author:

\section{Giuseppina Cerrato}

Tel.+390116707534, fax +390116707855, e-mail: giuseppina.cerrato@unito.it 


\section{Abstract}

Carbon storage in geological formations relies on knowledge of the effect of carbonate ligand formation for both dissolution and mineralisation to permit realistic reservoir modelling and to enhance confidence in storage security both spatially and temporally. Reaction rates are intrinsically slow and thus are not amenable to in-situ study, often determined from high pressure batch reactions providing largely bulk structural information through product analysis. Here we present a methodology to prepare silicate mineral analogues by placing reactive cations $(\mathrm{Na}$ and $\mathrm{Ca}$ ) on the surface of amorphous silica, greatly enhancing the rate of carbonate formation. Traditional characterisation techniques provide thorough structural and morphological information related to the effects of doping. In-situ Fourier Transform infrared spectroscopy (FTIR) is used to follow carbonate formation upon exposure to $\mathrm{CO}_{2}$. Carbonate speciation is found to be cation dependent and sensitive to the presence of water. Speciation shows further dependence on whether water is present during $\mathrm{CO}_{2}$ exposure or subsequently. Low pressure $\mathrm{CO}_{2}$ adsorption isotherms $\left(T=35^{\circ} \mathrm{C}\right)$ were measured to quantify carbonate formation, were fitted to an empirical adsorption isotherm model and related to cation coverage as determined by Energy-dispersive X-ray spectroscopy (EDX). $\mathrm{CO}_{2}$ uptake at low pressure was related to carbonate formation on the surface and at higher pressures was shown to depend on surface area as modified by cation adsorption. Although envisaged as mineralisation analogues, this system provides information on the impact of water on the formations of carbonates relevant to wider carbon capture and storage processes at the fundamental molecular level. 


\section{Introduction}

Carbon capture and storage (CCS) represents a leading technology in the global endeavor to reduce the exponentially increasing levels of anthropogenic $\mathrm{CO}_{2}$ present in the atmosphere, ${ }^{1-3}$ now an issue of widespread concern due to the status of $\mathrm{CO}_{2}$ as the primary contributor to global warming. ${ }^{4-6}$ CCS encompasses a number of technological processes which span its three central stages: capture, transport and storage. $\mathrm{CO}_{2}$ can be captured by: post-combustion separation of $\mathrm{CO}_{2}$ from a mixed flue gas following a combustion process; pre-combustion separation of $\mathrm{CO}_{2}$ and $\mathrm{H}_{2}$ following gasification or reforming and finally oxyfuel combustion of fossil fuels in pure $\mathrm{O}_{2}$ to produce $\mathrm{CO}_{2}$ and $\mathrm{H}_{2} \mathrm{O}$.

Capture processes utilizing different physical or chemical principles have been proposed. Leading industrial technologies use powerful physical (Selexol ${ }^{\mathrm{TM}}$ and Rectisol®) or chemical (monoethanolamine) solvents to deal with the low partial pressures of $\mathrm{CO}_{2}$ present in a typical flue gas. The regeneration energy requirement of the solvent is the main drawback and therefore alternative capture processes have been proposed that have lower parasitic energy requirements. Physisorption on high surface area materials facilitated by temperature or pressure swing, chemisorption on functionalized surfaces (e.g. amine grafted silica) ${ }^{7}$ and reversible metal oxide carbonation looping cycles (e.g. calcium looping) $^{8}$ have all been proposed as potential second generation capture processes. Direct capture of $\mathrm{CO}_{2}$ from air is more challenging and usually negatively impacted by water, ${ }^{9}$ although a recent report has utilized water to affect a swing process in direct air capture. ${ }^{10}$ 
After pressurization and drying to a supercritical fluid, $\mathrm{CO}_{2}$ is transported by pipeline to a suitable storage site. ${ }^{11}$ The storage of $\mathrm{CO}_{2}$ involves injection into one of a number of types of geological features, preventing its emission into the atmosphere, typically saline aquifers, depleted oil and gas reservoirs or deep coal seams. ${ }^{12}$

Both saline aquifers and depleted reservoirs are geological formations of water-permeable porous minerals saturated with brine. A common geological storage strategy is the injection of supercritical $\mathrm{CO}_{2}\left(\mathrm{scCO}_{2}\right)$ into such a formation, whereby it can undergo various reactive transport processes ultimately leading to storage. ${ }^{11}$ Stratigraphic or structural trapping occurs immediately upon injection of $\mathrm{CO}_{2}$ and is achieved by a sealing caprock (an impermeable geological feature). Solubility trapping occurs upon dissolution of $\mathrm{CO}_{2}$ into the formation brine ${ }^{13}$ and as this plume migrates through the aquifer residual trapping occurs due to capillary forces of the porous mineralogy. ${ }^{14}$ Finally, mineralisation occurs due to dissolution of mineral cations, initiated by the $\mathrm{pH}$ drop associated with $\mathrm{CO}_{2}$ injection. Subsequent reaction of dissolved $\mathrm{CO}_{2}$ species with the aforementioned cations can result in the formation of inorganic carbonates. It is of importance for all of the trapping mechanisms to understand wettability changes and carbonate formation. The reaction of $\mathrm{CO}_{2}$ with existing minerals to form stable inorganic carbonates offers a physically and temporally secure storage mechanism and as such this key fundamental process is the focus of the present study.

Mineralisation at high pressure in geological formations (in situ) is suitable for large scale emission scenarios but can also be applied in aqueous solution at source (ex situ) for small/medium emitters. ${ }^{15,16}$ In the naturally occurring process known as 'weathering', calcium or magnesium from silicate materials react with $\mathrm{CO}_{2}$ dissolved in brine to form stable calcium or magnesium carbonates. Efforts to replicate this process during injection 
of $\mathrm{scCO}_{2}$ would result in products that are both a secure store for anthropogenic $\mathrm{CO}_{2}$ and environmentally benign. ${ }^{17}$ The idea of mimicking such a process as a sequestration method to store anthropogenic $\mathrm{CO}_{2}-$ known as " $\mathrm{CO}_{2}$ sequestration by mineral carbonation (MC)" - was first proposed by Seifritz in $1990^{18}$ and over the past two decades much effort on the topic has focused on $M C$ becoming an economically viable sequestration technology, capable of fixing many megatonnes of the world's anthropogenic $\mathrm{CO}_{2} \cdot{ }^{19-23}$ Indeed injection projects include Sleipner (Norway), In Salah (Algeria), Ketzin (Germany), Weyburn (Canada), K12-B (Netherlands) and Snøhvit (Norway) where no unacceptable impact on safety or the environment have been reported. ${ }^{24}$

$\mathrm{CO}_{2}$ sequestration in carbonates can be achieved through a number of process routes which fall under two main categories. Direct carbonation (DC) involves carbonation of a $\mathrm{Ca} / \mathrm{Mg}$ rich solid in a single step either by gas-solid carbonation or direct aqueous mineral carbonation. Alternatively, indirect carbonation (IC), in which the first step is the extraction of the reactive cation from the $\mathrm{Mg} / \mathrm{Ca}$ oxide, silicate, carbonate or hydroxide from the mineral feedstock, then reaction of the leached cations with $\mathrm{CO}_{2}$ to form the carbonate. ${ }^{25}$ Intuitively, geological sequestration is an indirect carbonation process, with the aforementioned $\mathrm{pH}$ changes due to $\mathrm{CO}_{2}$ injection facilitating the extraction of the reactive cation through mineral dissolution.

A fundamental barrier to the monitoring of such a reaction over laboratory timescales is the slow reaction kinetics of the mineralisation reaction, primarily due to the time taken for dissolution of the silica layers to expose metal oxide sites reactive to $\mathrm{CO}_{2}$, however it is known that the formation of carbonate ligands can promote dissolution. ${ }^{26}$ One way to overcome the slow reaction rate inherent to mineral dissolution is the creation of a 
synthetic analogue - a simple silicate material whereby the reactive sites (alkali cations) are artificially placed on the surface rather than within the bulk structure by a method of cation-exchange. Alkali-feldspars and plagioclase feldspars are alkali metal containing aluminosilicate minerals relevant to $\mathrm{CO}_{2}$ storage ${ }^{27}$ and as such an effort has been made to replicate a representative but artificially reactive surface to enable spectroscopic investigation of carbonate formation on these cations. Silica tetrahedra are a common substituent structure in subsurface geological storage locations as are alkali and alkaline earth cations. Quartz, mica, clays and silicate minerals all contain silica tetrahedra with interstitial cations or the possibility for cation-exchange with surface hydroxyl groups. Thus our synthetic model provides the opportunity to study carbonate formation on a surface with chemical relevance for solids of interest for geological sequestration of $\mathrm{CO}_{2}$, but also on a wider range of capture materials where carbonate formation and the influence of water is of interest.

In order to exploit this advantage, in the present study, $\mathrm{SiO}_{2}$ materials modified by $\mathrm{Na}$ or Ca were prepared by a cation-exchange method with surface hydroxyl groups. The investigation describes their subsequent characterisation, with primary aims of assessing the effect of the introduction of the surface cation on textural and structural properties of the parent material. Most importantly, the speciation of carbonates formed initially and in the presence or absence of water was studied. Quantification of carbonate formation and cation-exchange was conducted and related to the surface chemistry of the material in the context of carbon storage. 


\section{Experimental}

\subsection{Sample preparation}

The preparation of the cation-doped $\mathrm{SiO}_{2}$ materials used an ion-exchange procedure, based on a method previously reported for the synthesis of $\mathrm{K}$-modified $\mathrm{SiO}_{2}{ }^{32}$ The procedures for the mono and divalent cation-doped materials varied slightly in the use of the precursor reagents.

In the case of monovalent ion-exchange, a carbonate salt is able to produce the high $\mathrm{pH}$ required to drive ion-exchange with surface hydroxyl groups, along with a reasonable concentration of cations in solution available for exchange. However, due to the low solubility of the divalent carbonate/hydroxide salts, a saturated solution of the hydroxide was employed (to attain high $\mathrm{pH}$ ), which after filtration was used as the solution in which a neutral salt, the respective chloride, was dissolved (to attain reasonable concentration of cation). The solubility of the hydroxide was so low at room temperature (r.t.) that it should not impact the concentration of the solution measurably.

Na-SiO 2 : A $0.5 \mathrm{M}$ solution of $\mathrm{Na}_{2} \mathrm{CO}_{3}$ was made up using $10.599 \mathrm{~g} \mathrm{Na}_{2} \mathrm{CO}_{3}$ (Sigma-Aldrich ACS Reagent $\geq 99.5 \%)$ in $200 \mathrm{~mL}$ UP Grade 1 water $(18.2 \mathrm{~m} \Omega \mathrm{cm})$. This solution was transferred to a $250 \mathrm{ml}$ beaker containing $10 \mathrm{~g}$ of $\mathrm{SiO}_{2}$ and stirred continuously for $2 \mathrm{~h}$ with the $\mathrm{pH}$ recorded every $30 \mathrm{~s}$ using an automatic $\mathrm{pH}$-meter until equilibrium was achieved. The resulting solution was vacuum filtered, washed twice with filtrate and dried at $70{ }^{\circ} \mathrm{C}$ for $24 \mathrm{~h}$.

Ca-SiO 2 : A saturated solution of $\mathrm{Ca}(\mathrm{OH})_{2}$ (Sigma-Aldrich, Puriss P.A. Reag. Ph. Eur) in Grade 1 UP water $(18.2 \mathrm{~m} \Omega \mathrm{cm})$ was prepared, stirred at r.t. for 15 minutes and filtered to remove the solid. A $0.5 \mathrm{M}$ solution of $\mathrm{CaCl}_{2}$ was made up using $22.193 \mathrm{~g} \mathrm{CaCl}_{2}(\mathrm{BDH}$, 
fused granular, 3-8 mesh) in $200 \mathrm{~mL}$ of $\mathrm{Ca}(\mathrm{OH})_{2}$ saturated solution, and procedure followed as above.

$\mathrm{SiO}_{2}$ reference material (EP10, Crossfield Organics) was used as purchased from the company.

All the samples were characterized both in the as prepared form and after calcination at $450^{\circ} \mathrm{C}$.

\subsection{Specific Surface Area \& Porosity}

The specific surface area and porosity of reference $\mathrm{SiO}_{2}$ and both the cation-doped samples were determined using a Micromeritics ASAP 2010 with $\mathrm{N}_{2}$ as the adsorbate gas and coolant. Prior to $\mathrm{N}_{2}$ sorption, samples were degassed overnight at r.t. to remove any physically adsorbed species from the sample surfaces and clean the surface of any contaminants. Full adsorption-desorption isotherms were determined volumetrically by a discontinuous static method at $77 \mathrm{~K}$. The Brunauer-Emmett-Teller (BET) method was applied to these isotherms to determine the specific surface area, and the Barrett-JoynerHalenda (BJH) method to the adsorption branch to determine pore volume and size distribution.

\subsection{X-Ray Diffraction (XRD)}

Powder XRD patterns of the samples were recorded using a Philips Powder/Thin Film PW3020 X'Pert diffractometer equipped with a PW3820 goniometer, using Cu-Ka radiation $(1.5418 \AA$ A ) and Bragg-Brentano geometry. Samples were ground thoroughly in a mortar and transferred to an amorphous glass sample holder for measurement. 


\subsection{FTIR Spectroscopy}

Transmission FTIR spectra of cation-doped samples, as well as the reference $\mathrm{SiO}_{2}$, were collected at beam temperature on a Perkin-Elmer System 2000 spectrophotometer equipped with a liquid nitrogen-cooled mercury-cadmium-telluride (MCT) cryo-detector, working in the range $7200-580 \mathrm{~cm}^{-1}$ at a resolution of $2.0 \mathrm{~cm}^{-1}$ (40 scans). Powdered samples were compressed into self-supporting discs (weighing $\sim 5-10 \mathrm{mg} \mathrm{cm}^{-2}$ ) and supported in a pure gold frame prior to transfer to a custom-made quartz cell, fitted with $\mathrm{KBr}$ windows, connected to a conventional high-vacuum line.

The IR characterisation was performed during outgassing at r.t. and after thermal treatment at $400{ }^{\circ} \mathrm{C}$ in vacuo $\left(<3.75 \times 10^{-4}\right.$ Torr $)$ of the as prepared samples. During the 2 $\mathrm{h}$ thermal treatment, the samples were periodically exposed to $22.5-30 \mathrm{Torr}_{2} \mathrm{O}_{2}$ to ensure any contaminants were completely removed, giving a clean surface for the following measurements.

$\mathrm{CO}_{2}$ and/or $\mathrm{H}_{2} \mathrm{O}$ adsorption/desorption measurements were carried out after the above mentioned thermal treatment in order to test the possible reactivity of the samples in experimental situations mimicking the chemistry of the mineral carbonation process.

\subsection{Adsorption measurements}

A volumetric chemisorption apparatus (Micromeritics ASAP 2020C) was used to measure low pressure $\mathrm{CO}_{2}$ isotherms on the as-prepared cation doped samples. Powders (ca. 0.5 g) were pre-treated at $400{ }^{\circ} \mathrm{C}$ in-vacuo $\left(<5.0 \times 10^{-6}\right)$ for $2 \mathrm{~h}$ as in the spectroscopic investigation before exposure to dry $\mathrm{CO}_{2}$ at $35{ }^{\circ} \mathrm{C}$. Measurements were conducted in triplicate with fresh sample, with the isotherms presented as the average. A Freundlich isotherm model was fitted to the measured isotherms through non-linear regression. 


\subsection{Energy-dispersive X-ray spectroscopy (EDX)}

EDX mapping of pelletised as-prepared samples was conducted with an Oxford INCA Energy Dispersive X-ray detector to determine sample composition and elemental distribution. Cation doping level was determined and presented as an average of multiple points with standard deviation. 


\section{Results and discussion}

\subsection{Textural and structural properties}

Values from specific surface area and porosity analysis of as prepared and calcined samples are presented in Table 1. As for the as prepared samples, the high surface area of the reference $\mathrm{SiO}_{2}$ was heavily modified by the exchange of the dopant cation, with differing results obtained for each. The same pattern is observed in the values of cumulative pore volume, with the monovalent cation causing the greatest reduction. Full BET isotherms and pore size distribution plots are given in the Supporting Information for as prepared (Figure S1) and calcined materials (Figure S2).

Table 1. BET surface area and BJH adsorption cumulative pore volume of the as prepared and calcined samples.

\begin{tabular}{|c|c|c|c|c|}
\hline \multirow{2}{*}{ Sample } & \multicolumn{2}{|c|}{ Surface Area $\left.\mathbf{( m}^{\mathbf{2}} \mathbf{g}^{-1}\right)$} & \multicolumn{2}{c|}{ Pore Volume $\left.\mathbf{( c m}^{\mathbf{3}} \mathbf{g}^{-1}\right)$} \\
\cline { 2 - 5 } & As prepared & Calcined & As prepared & Calcined \\
\hline $\mathrm{SiO}_{2}$ & 257 & 259 & 1.72 & 1.75 \\
\hline $\mathrm{Ca}-\mathrm{SiO}_{2}$ & 157 & 125 & 0.77 & 0.65 \\
\hline $\mathrm{Na}-\mathrm{SiO}_{2}$ & 93 & 79 & 0.52 & 0.44 \\
\hline
\end{tabular}

Two hypotheses can be proposed to account for the reduction in surface area and pore volume. First of all, it is reasonable to assume that the pore network of $\mathrm{SiO}_{2}$ has been partially dissolved due to the high $\mathrm{pH}$ synthesis conditions. At high $\mathrm{pH}$ when the surface is negatively charged due to ionisation, $\mathrm{Si}-\mathrm{O}$ bonds are polarised and weakened, enhancing 
dissolution and consequently destroying the porous network. ${ }^{28}$ It has also been observed that the presence of cations enhances the rate of silica dissolution. ${ }^{29-31}$

It is also reasonable that, across the surface, and hence also within the pores, there is a build-up of a secondary cation-containing phase in layers, such as oxide or hydroxidebased, as evidenced by FTIR results (see later). However it is unlikely to $100 \%$ pore fill. In terms of impact on carbon sequestration, it can be concluded that surface hydroxyl ion exchange with alkaline brine cations will lower both surface area and porosity, thus affecting reservoir permeability and subsequent injectivity. Any change to pore volume will have an impact on capillary pressure and thus plume migration and residual saturation of $\mathrm{ScCO}_{2}$

Following calcination, the surface area, pore volume and average pore diameter of the $\mathrm{SiO}_{2}$ sample remain unchanged, although a $15-20 \%$ reduction in surface area and pore volume is found for the doped samples. This reduction can be due to initial stages of silica crystallisation, enhanced by the presence of the cation, which has been evidenced in a previous investigation of $\mathrm{SiO}_{2}$ modified by $\mathrm{K}_{2} \mathrm{CO}_{3},{ }^{32}$ and is further confirmed, at least in the case of the Na-doped sample, by X-ray diffraction measurements (vide infra). During a crystallisation procedure, the particle size increases and pores begin to reduce in size and collapse, factors which reduce both surface area and pore volume (Table 1).

All of the as prepared and calcined samples give isotherms of Type IV, according to IUPAC classification. ${ }^{33}$ All isotherms also exhibit large Type $\mathrm{H} 1$ hysteresis loops, another feature characteristic of Type IV isotherms, as a consequence of capillary condensation in mesopores. Type $\mathrm{H} 1$ hysteresis is indicative of ink-bottle-shaped pores, whereby the entrance to the pore is much narrower than the pore itself. ${ }^{34}$ 
As for the structure retained by the samples as prepared, their main features observed by XRD are displayed in Figure $1 \mathrm{~A}$, in which the broad peak between $16-28^{\circ} 2 \theta$, centered at $21^{\circ} 2 \theta$, is specific to amorphous silica..$^{35-37}$

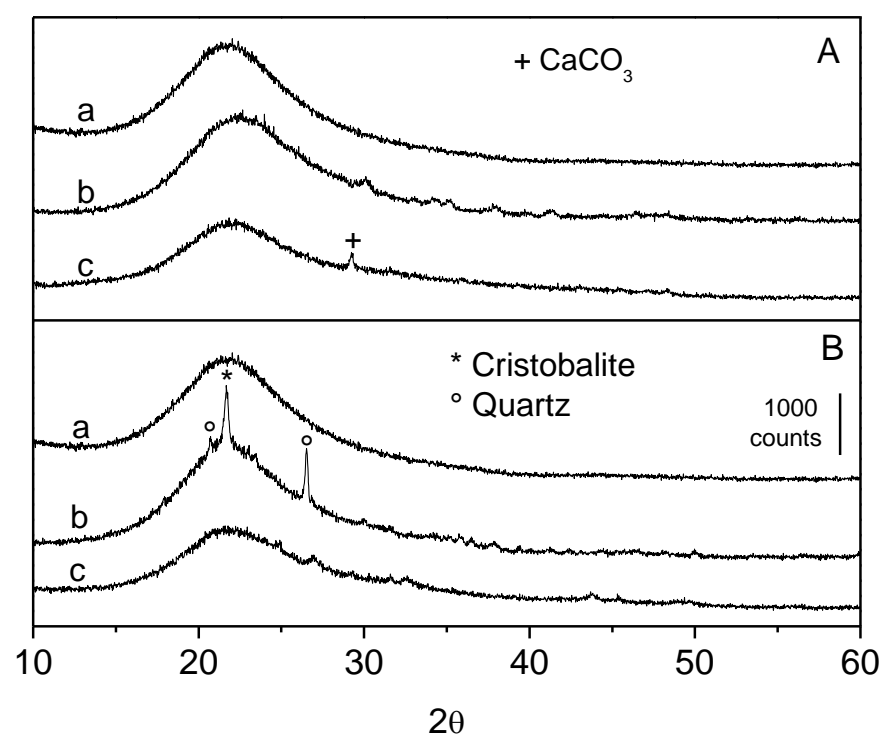

Figure 1 - XRD patterns of $\mathrm{SiO}_{2}(\mathrm{a}), \mathrm{Na}-\mathrm{SiO}_{2}$ (b) and $\mathrm{Ca}-\mathrm{SiO}_{2}$ (c) as prepared (section A) and after calcination at $450^{\circ} \mathrm{C}$ (section $\left.\mathrm{B}\right)$.

Both doped samples retain this characteristic halo, indicating that at preparation and drying temperatures, the amorphous character of the bulk silica is not affected by the dopant cation. In addition to this broad peak, a number of additional features are observed for the doped samples. The ill-defined, very low intensity peaks present in $\mathrm{Na}-\mathrm{SiO}_{2}$ (Figure $1 \mathrm{Ab})$ were not identified, but may indicate the presence of a non-stoichiometric phase in very small quantities, residues of the synthesis procedure. In the case of Ca-doping (Figure $1 \mathrm{~A} \mathrm{c}$ ) only one additional peak at $29.3^{\circ} 2 \theta$ is evident and reasonably assigned to the (104) reflection of the rhombohedral calcite phase of $\mathrm{CaCO}_{3}$ (ICDD 00-001-0837). 
In all cases, after calcination the characteristic broad halo of amorphous silica remains (Figure 1B). In particular, the Na-doped sample (Figure 1B,b) shows three peaks at 20.6, 21.6 and $26.5^{\circ} 2 \theta$ assigned to cristobalite and quartz phases. As mentioned above, this result demonstrates that the presence of the cation encourages the early onset of silica crystallisation with respect to other samples; Ca-doped sample (Figure 1B,c) shows no distinct peaks and the peak previously assigned as $\mathrm{CaCO}_{3}$ disappeared, consistent with the removal of carbonate species after heat treatment (also demonstrated by FTIR analysis: vide infra).

\subsection{FTIR characterization}

Spectral features for the pure silica sample (Figure 2, a) include bands at 3738, 3660 and $3530 \mathrm{~cm}^{-1}$, more readily seen after outgassing, which can be assigned to the stretching mode of isolated, bridging, and hydrogen-bonded silanol (Si-O-H) groups, respectively. ${ }^{38}$ The additional band at $1631 \mathrm{~cm}^{-1}$ is representative of the bending mode $\delta(\mathrm{OH})$ of $\mathrm{H}_{2} \mathrm{O}$ hydrogen-bonded to the surface and the associated stretching mode $v(\mathrm{OH})$ is present at $3250-3500 \mathrm{~cm}^{-1}$. After evacuation, it is evident that while the bridging and hydrogenbonded silanols are reduced in intensity, the band due to isolated Si-O-H groups increased in intensity indicating these species to be stable to outgassing. It is clear that the surface water is almost completely removed on outgassing at r.t., as illustrated by the reduction in intensity of the $\delta(\mathrm{OH})$ and $v(\mathrm{OH})$ bands.

In general, the above observations are consistent for both doped materials (Figure 2, b and c sets of spectra), with any marked differences discussed below. 


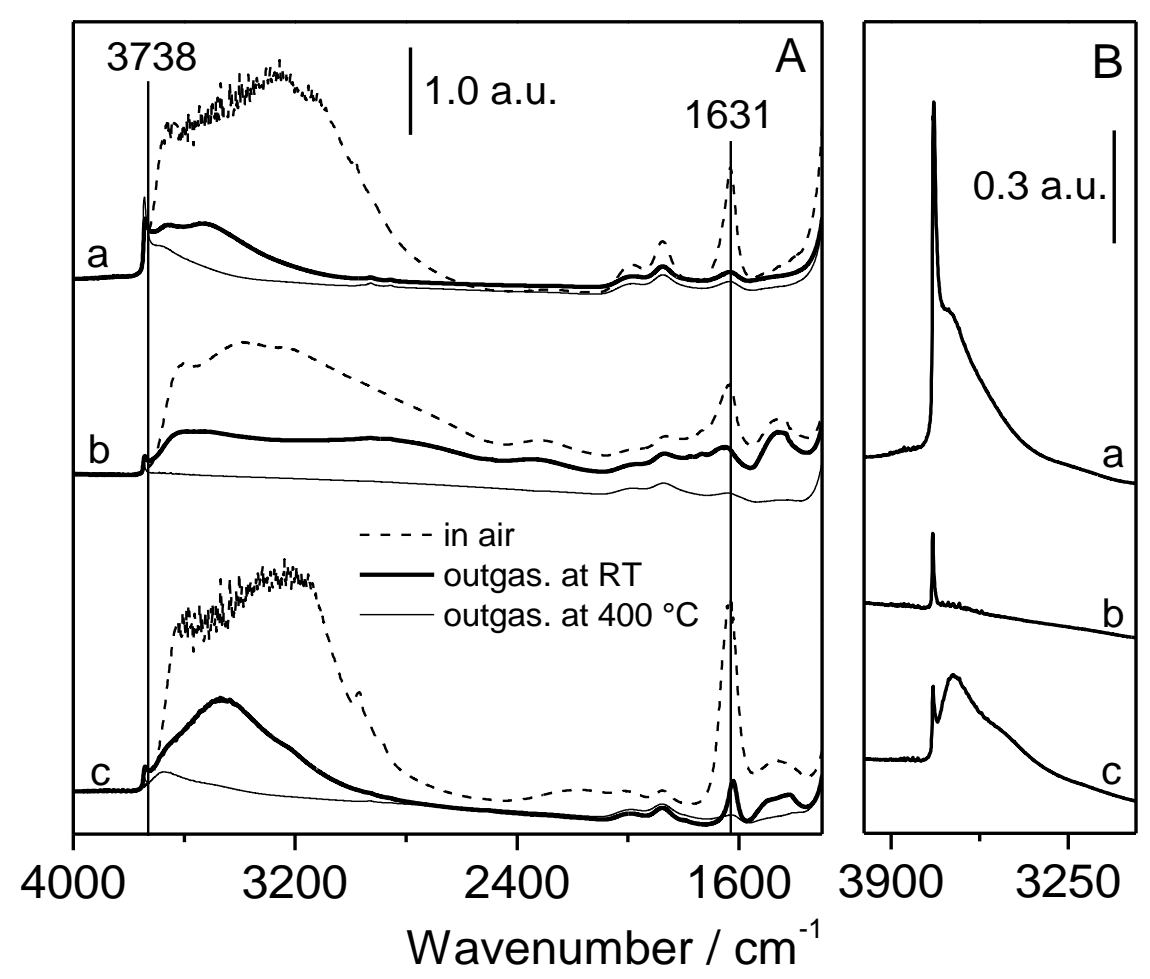

Figure 2 - Section A: FT-IR spectra of $\mathrm{SiO}_{2}(\mathrm{a}), \mathrm{Na}^{-\mathrm{SiO}_{2}}$ (b) and $\mathrm{Ca}-\mathrm{SiO}_{2}(\mathrm{c})$ in air (dashed lines) and after outgassing at r.t. (solid bold lines) and at $400{ }^{\circ} \mathrm{C}$ (solid lines). Section B: zoom in the free hydroxyl region of the spectra recorded after outgassing at 400 ${ }^{\circ} \mathrm{C}$.

The affinity of each sample for $\mathrm{H}_{2} \mathrm{O}$ (dashed lines in Figure $2 \mathrm{~A}$ ), the hydrophilicity, differs depending on the nature of the dopant. Looking at the intensity of the $\delta(\mathrm{OH})$ mode at 1631 $\mathrm{cm}^{-1}$ as well as the corresponding stretching mode $v(\mathrm{OH})$, present as part of the broad band between $3000-3500 \mathrm{~cm}^{-1}$, it is evident that $\mathrm{Na}$ appears to decrease the hydrophilicity of the sample relative to pure silica, whereas the presence of $\mathrm{Ca}$ causes a more significant increase in $\mathrm{H}_{2} \mathrm{O}$ affinity. This has an important impact for $\mathrm{CO}_{2}$ sequestration, as wettability is one factor which will impact the efficiency of storage, determining the distribution of the 
fluid phase within the reservoir. If water wettability is decreased, $\mathrm{CO}_{2}$ wettability will increase. In turn $\mathrm{CO}_{2}$ will fill small pores and form a film on the surface, potentially enhancing injectivity. ${ }^{39}$ However, the use of FTIR is not appropriate to determine quantitative indications about wettability and as such should be strictly limited to hydrophilicity interpretation, where the relationship to wettability is speculative in nature. Contact angle measurements would be more appropriate to describe wettability.

After evacuation at r.t. and at $400{ }^{\circ} \mathrm{C}$, the free silanol peak at $3738 \mathrm{~cm}^{-1}$ (see section $\mathrm{B}$ of Figure 2) is markedly reduced for doped samples with respect to pure $\mathrm{SiO}_{2}$ : this is expected as the process of doping included an ion exchange with $\mathrm{OH}$ groups.

An additional feature of the $v(\mathrm{OH})$ region, observable for $\mathrm{Na}^{-\mathrm{SiO}_{2}}$ in air and after outgassing at r.t., is the presence of a broad band between $3000-2750 \mathrm{~cm}^{-1}$. Though the identity of this cannot be concluded with certainly at this stage, if the model of a cationbased oxide-like phase building up on the surface of the $\mathrm{SiO}_{2}$ is considered, an assignment can be postulated. Such a non-stoichiometric oxide-like phase would, in the presence of atmospheric $\mathrm{H}_{2} \mathrm{O}$, exist as a 'hydroxide-like' phase, terminating in an $\mathrm{OH}$ group different from an isolated (or bonded) silanol on the surface of the $\mathrm{SiO}_{2}$ base, with a unique $\mathrm{O}-\mathrm{H}$ stretching mode. It is therefore suggested that this highlighted feature in the $v(\mathrm{OH})$ region, persistent also on outgassing at r.t., may be assigned in this way. This may also be the reason for a smaller shoulder in the $\mathrm{Ca}-\mathrm{SiO}_{2}$ spectrum at around $3250 \mathrm{~cm}^{-1}$, clearly observed after outgassing at r.t.

Spectra recorded upon exposure to $\mathrm{CO}_{2}$ at r.t. with $\mathrm{Na}-\mathrm{SiO}_{2}$ (Figure $3 \mathrm{~A}$ ) and $\mathrm{Ca}-\mathrm{SiO}_{2}$ (Figure 3B) are reported. Spectra for $\mathrm{SiO}_{2}$ are not reported since no bands were observed in this region. 


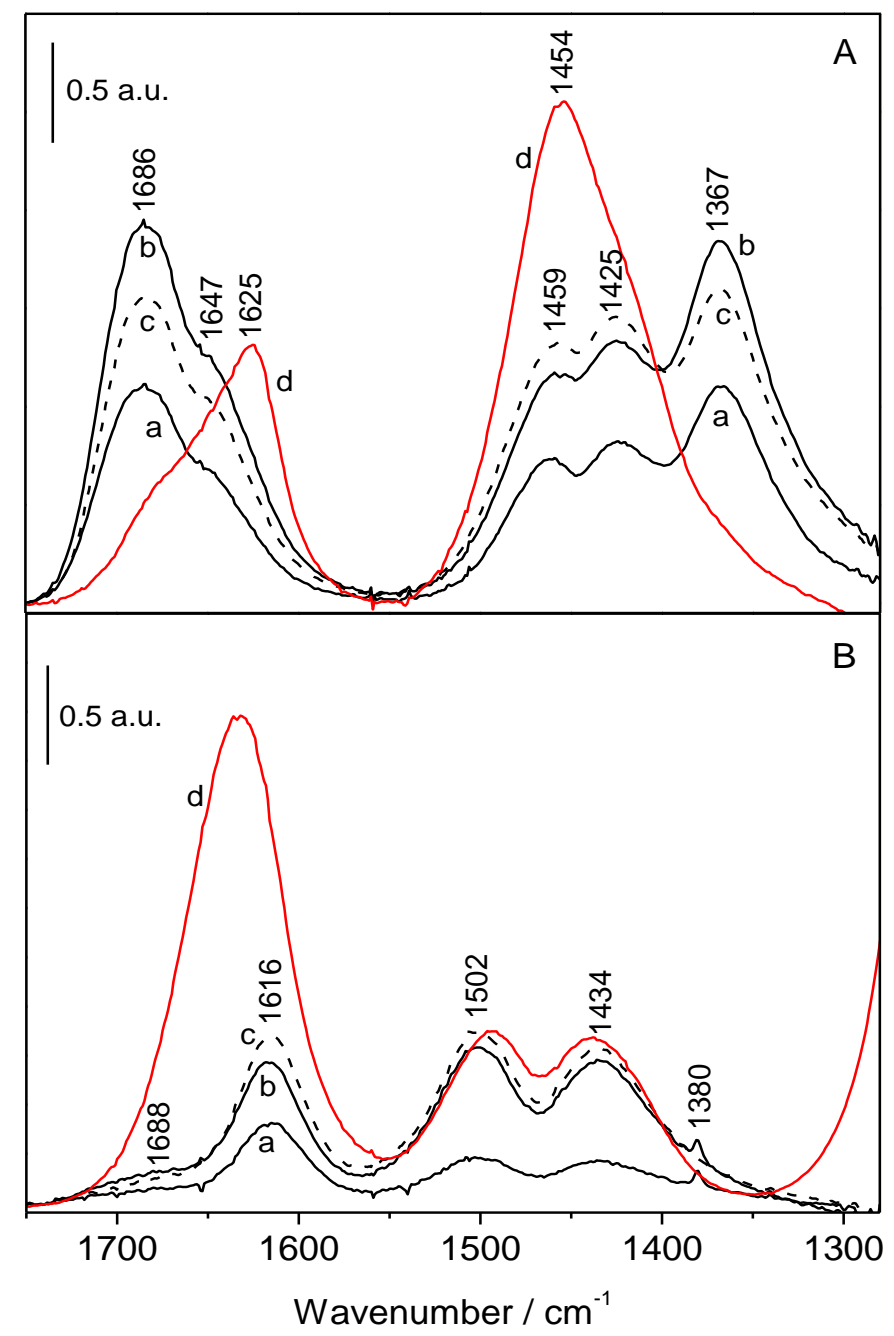

Figure 3 - FT-IR spectra of $\mathrm{Na}_{-} \mathrm{SiO}_{2}(\mathrm{~A})$ and $\mathrm{Ca}-\mathrm{SiO}_{2}(\mathrm{~B})$ upon admission of $3.75 \mathrm{Torr}(\mathrm{a})$ and 15 Torr (b) of $\mathrm{CO}_{2}$ at r.t. Dashed spectra (c) and red spectra (d) are recorded after $\mathrm{CO}_{2}$ outgassing at r.t. and subsequent $\mathrm{H}_{2} \mathrm{O}$ admission (9 Torr) at r.t., respectively.

As for $\mathrm{Na}-\mathrm{SiO}_{2}$, five defined peaks are evident. Based on the changes in intensity of the peaks upon outgassing (Figure 3A, c), it can be concluded that the pair of peaks at 1686 and $1647 \mathrm{~cm}^{-1}$ and that at $1367 \mathrm{~cm}^{-1}$ are associated, as are the pair at 1459 and 1425 $\mathrm{cm}^{-1}$. The first set of peaks are assigned to bidentate carbonates and the second as ionic carbonates ${ }^{40,41} \mathrm{It}$ is proposed that a lower frequency partner to the peak at $1647 \mathrm{~cm}^{-1}$ may 
also be present, but the band is not resolved from those of the ionic species. This result is similar to results obtained by Bal et al. for the formation of carbonate species on alkalimetal oxide loaded silica, $\mathrm{Na}_{2} \mathrm{O}-\mathrm{SiO}_{2}{ }^{42}$ This is the first significant evidence to support the proposed surface model of an oxide-like phase, in this case sodium oxide, building up on top of $\mathrm{SiO}_{2}$.

In accordance with previously reported data for the oxide species, ${ }^{43} \mathrm{Ca}-\mathrm{SiO}_{2}$ (Figure $3 \mathrm{~B}$ ) shows evidence of monodentate carbonate formation with a pair of bands present at 1502 and $1434 \mathrm{~cm}^{-1}$. Another prominent band at $1616 \mathrm{~cm}^{-1}$ is associated with the bending mode of hydrogen-bonded $\mathrm{H}_{2} \mathrm{O}$, potentially linked with the earlier observation of higher hydrophilicity of this sample. Additional peaks are visible at 1688 and $1380 \mathrm{~cm}^{-1}$, which are absent in spectra of sample after outgassing (Figure $3 \mathrm{~B}$, dashed line $\mathrm{c}$ ): they are tentatively assigned to bicarbonate species and/or in the case of the $1380 \mathrm{~cm}^{-1}$ component to the $v_{1}$ mode of molecularly adsorbed $\mathrm{CO}_{2}{ }^{40,44}$ Upon removal of these on evacuation, bands due to the monodentate species increase in intensity, suggesting interconversion between the two carbonate species.

As for the interaction of $\mathrm{CO}_{2}$ with surface ions, namely $\mathrm{OH}$ groups, it must be recalled that some indications may come from the inspection of the spectral region typical of the $v_{3}$ mode of the molecule (Figure S3). It is interesting to note that one simple component is present in the case of plain $\mathrm{SiO}_{2}$ (located at $\sim 2345 \mathrm{~cm}^{-1}$ ), which remains also in the case of the cation-modified materials, even though in the case of the Na-modified one it exhibits a much lower intensity with respect to the others. This intensity trend reflects the different $\mathrm{OH}$ populations exhibited by the samples, as reported in Figure 2B.

Admission of $\mathrm{H}_{2} \mathrm{O}$ was subsequently performed on samples from the previously described $\mathrm{CO}_{2}$ admission experiments (Figure 3, red curves d). As it is likely that $\mathrm{H}_{2} \mathrm{O}$ is present in 
some form, most likely brine during the mineralisation process and long-term storage, this investigation was performed to test the effect of wettability changes and the stability of carbonate species.

For $\mathrm{Na}-\mathrm{SiO}_{2}$ sample, the presence of $\mathrm{H}_{2} \mathrm{O}$ led to the conversion of bidentate species (bands at 1686, 1647 and $1367 \mathrm{~cm}^{-1}$ ) to highly symmetrical ionic carbonates, with one band present at $1454 \mathrm{~cm}^{-1}$, instead of the two bands at 1459 and $1425 \mathrm{~cm}^{-1}$ for the ionic carbonates under dry conditions. The second prominent band at $1625 \mathrm{~cm}^{-1}$ is related to the bending mode of $\mathrm{H}_{2} \mathrm{O}$. Both bands have ill-defined shoulders on the high and low frequency sides, respectively, which most likely contain components of residual bidentate species and potentially ionic species of differing symmetry, less symmetric than those giving the single peak. A similar effect was observed for nitrate species adsorbed on a $\mathrm{BaO}$ phase ${ }^{45}$ where it was demonstrated that the dissociative adsorption of water leading to $\mathrm{OH}$ groups causes the transformation of bidentate nitrates to an ionic form. The extent of transformation decreases upon increasing temperature in relation to the decreased surface hydroxylation. The same behaviour was observed for sulfated $\mathrm{ZrO}_{2}: 46$ surface hydration of the solid affects the structure and, consequently, the IR spectra of surface sulfates. On hydrated surfaces, sulfates have been reported to be present predominantly in an ionic configuration resembling that of inorganic sulfato-complexes, whereas on dehydrated surfaces the sulfates tend to acquire a configuration similar to that of the organic sulfonic derivatives. It is possible to propose that the dissociative adsorption of water takes place in a competitive manner on surface sites on which, in our case, bidentate carbonates are formed. This displaced species remain on areas of the surface suitable for the formation of the ionic species. 
These findings show that the presence of water at the carbonation site could have a direct impact on the carbonate speciation during mineralisation. As carbonate coordination will impact on the packing efficiency of the carbonate layer, it is possible to speculate that the carbonation efficiency will be subsequently affected. Of course the difference in pressure between the current investigation and reservoir conditions is likely to impact this further.

For $\mathrm{Ca}-\mathrm{SiO}_{2}$ sample, the only observable effect of water is the significant increase in intensity of the peak at $1616 \mathrm{~cm}^{-1}$ due to the $\mathrm{H}_{2} \mathrm{O}$ bending mode; no changes to the carbonate species were observed.

A second investigation on the effect of water was also performed with co-admission of $\mathrm{H}_{2} \mathrm{O}$ and $\mathrm{CO}_{2}$, testing the effect of $\mathrm{H}_{2} \mathrm{O}$ on the carbonate formation process over longer periods of time (up to 20 hours). In this case, co-admission of $\mathrm{CO}_{2}$ at the maximum pressure admitted in the previous investigation - 15 Torr - and $\mathrm{H}_{2} \mathrm{O}$ was made (Figure 4).

The pressure of $\mathrm{H}_{2} \mathrm{O}$ selected was 9 Torr, based on comparisons between $\mathrm{H}_{2} \mathrm{O}$ admission spectra (not reported for sake of brevity) and that of the samples in air: 9 Torr corresponds roughly to the level of $\mathrm{H}_{2} \mathrm{O}$ present in the sample as prepared.

As for $\mathrm{Na}_{-} \mathrm{SiO}_{2}$ sample (Figure $4 \mathrm{~A}$ ), by comparing the spectra obtained in the previous study (Figure 3A, red curve d), it is immediately apparent that the initial situation here (Figure $4 \mathrm{~A}, \mathrm{a}$ ) is the same as the final in that case, i.e. two prominent bands, one at $\sim 1460$ $\mathrm{cm}^{-1}$ representing ionic carbonates and the bending mode of $\mathrm{H}_{2} \mathrm{O}$ at $1632 \mathrm{~cm}^{-1}$, with shoulders of additional species also visible. However, after prolonged exposure to the $\mathrm{CO}_{2} / \mathrm{H}_{2} \mathrm{O}$ mixture, a decline in the intensity of the ionic band is clearly observed, with simultaneous increase of bands at around $1370-1390 \mathrm{~cm}^{-1}$ and $1674 \mathrm{~cm}^{-1}$. 


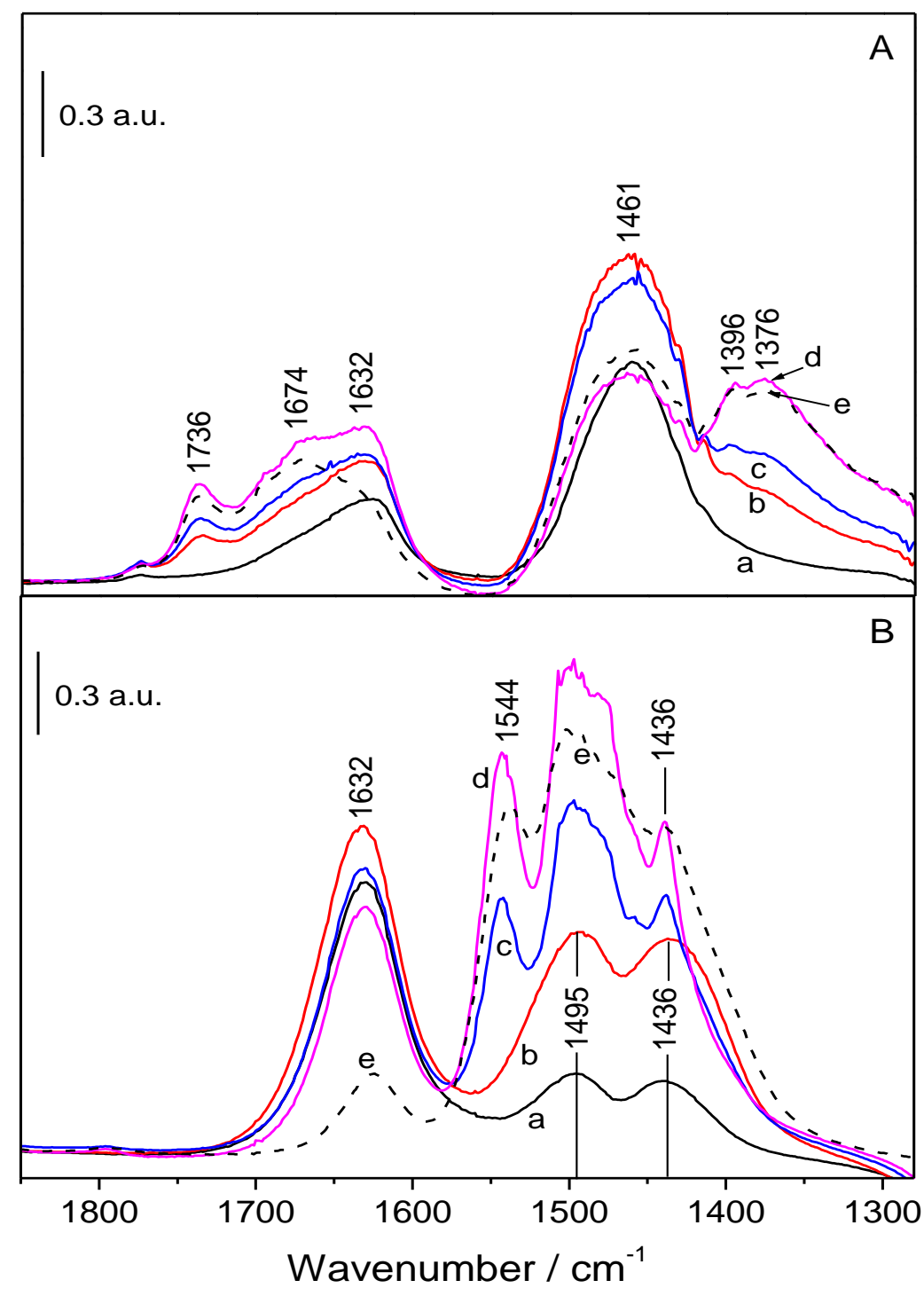

Figure 4 - FT-IR spectra of $\mathrm{Na}-\mathrm{SiO}_{2}(\mathrm{~A})$ and $\mathrm{Ca}-\mathrm{SiO}_{2}(\mathrm{~B})$ upon admission of $\mathrm{CO}_{2} / \mathrm{H}_{2} \mathrm{O}$ mixture ( $\mathrm{p}_{\mathrm{CO} 2}=15$ Torr, $\mathrm{pH}_{2} \mathrm{O}=9$ Torr) at r.t. for increasing contact time: $1 \mathrm{~min}(\mathrm{a}), 30 \mathrm{~min}$ (b), 2 hours (c) and 20 hours (d). Dashed spectra (e) are recorded after $\mathrm{CO}_{2} / \mathrm{H}_{2} \mathrm{O}$ outgassing at r.t.

The positions of these bands are consistent with expectation for bidentate carbonate species, which suggests a return to the original species seen following $\mathrm{CO}_{2}$ exposure 
alone (Figure 3A, a and b). Upon outgassing, the band due to the $\mathrm{H}_{2} \mathrm{O}$ bending mode is visibly decreased, and to a lesser extent as are the bands of the bidentate carbonates, though the remaining ionic species appear more stable to evacuation. A conversion of ionic to covalent carbonates is apparent due to surface dehydroxylation during the outgassing process in agreement with the hydroxylation/dehydroxylation effect mentioned above.

$\mathrm{Ca}-\mathrm{SiO}_{2}$ sample also presents a complex series of spectra (Figure 4B), though the initial situation remains similar to that of $\mathrm{CO}_{2}$ admission only (and subsequent $\mathrm{H}_{2} \mathrm{O}$ admission on top of formed carbonates), presented earlier (Figure 3B), with the exception of the $\mathrm{H}_{2} \mathrm{O}$ bending mode, significantly more prominent here as expected. Interesting developments occur after 1-2 $\mathrm{h}$ of exposure (Fig 4B c), with growth of a new band at $1544 \mathrm{~cm}^{-1}$ and replacement of the broad band at about $1436 \mathrm{~cm}^{-1}$ with a narrower feature in the same position. In addition, the band at about $1495 \mathrm{~cm}^{-1}$ changes shape and prominently increases in intensity. These new and modified bands are attributed to a new pair of monodentate $\left(1544\right.$ and $\left.1436 \mathrm{~cm}^{-1}\right)$ and ionic $\left(1495 \mathrm{~cm}^{-1}\right)$ carbonates with the original monodentate carbonates converting to these forms by the hydroxylation process. On outgassing, some of the ionic and "new" monodentate species appear to transform back into the original carbonates, as a shoulder potentially of the wide initial peak is observed to form at $\sim 1400 \mathrm{~cm}^{-1}$ (Figure 4B, e). Also in this case, this observation can be related to surface dehydroxylation during the outgassing process, in agreement with the hydroxylation/dehydroxylation effect mentioned above. 


\subsection{Adsorption measurements and metal loading}

Experimentally determined $\mathrm{CO}_{2}$ adsorption isotherms are presented (Figure 5) for $\mathrm{Ca}_{-} \mathrm{SiO}_{2}$ (red circles) and $\mathrm{Na}_{-} \mathrm{SiO}_{2}$ (black squares) with fitting (red lines) by the Freundlich isotherm equation $\left(q=\mathrm{K}_{\mathrm{f}} p^{1 / n}\right)$. Freundlich isotherm parameters and regression coefficients are given in Table 2. Repeatability was checked by running isotherms in triplicate on fresh samples, with standard deviation error bars $(n=3)$ smaller than the data points shown in Figure 5 , indicating a high level of repeatability. The data showed an increase in the quantities adsorbed with increasing $\mathrm{CO}_{2}$ pressure but failed to attain a plateau within the pressure range studied, indicating that further adsorption would occur at higher pressures for both doped samples.

Experimentally determined data points were fitted through non-linear regression to the Freundlich isotherm equation $\left(q=\mathrm{K}_{\mathrm{f}} p^{1 / \mathrm{n}}\right)$, an empirical model suitable for non-ideal adsorption on heterogeneous surfaces as well as for multi-layer adsorption. $\mathrm{K}_{\mathrm{f}}$ is the Freundlich isotherm constant and $\mathrm{n}$ is the adsorption intensity, empirical parameters related to adsorption capacity and strength respectively. Regressions coefficients (Table 2) show that the Freundlich isotherm fitted the data well and suggested the above hypotheses are correct. The maximum adsorption at 760 Torr $\left(T=35^{\circ} \mathrm{C}\right)$ calculated using the fitting parameters was 0.22 and $0.13 \mathrm{mmol} \mathrm{g}^{-1}$ for $\mathrm{Ca}-\mathrm{SiO}_{2}$ and $\mathrm{Na}-\mathrm{SiO}_{2}$, respectively. As the former sample has been shown to be more hydrophilic and that a greater amount of surface hydroxyl groups were present after evacuation (Figure 2) it is possible that this surface functionality enhanced $\mathrm{CO}_{2}$ uptake. Hydroxyl groups have a high affinity for $\mathrm{CO}_{2}$ and their presence encourages bicarbonate formation and higher sorption values. ${ }^{47}$ However, when the different surface areas of the materials were considered (Table 1), a clear relationship between final $\mathrm{CO}_{2}$ uptake and post-synthesis surface area was 
apparent. Values normalised per unit area (Table 1) are $1.40 \mu \mathrm{mol} \mathrm{m}{ }^{-2}$ for both $\mathrm{Ca}_{-} \mathrm{SiO}_{2}$ and $\mathrm{Na}-\mathrm{SiO}_{2}$.

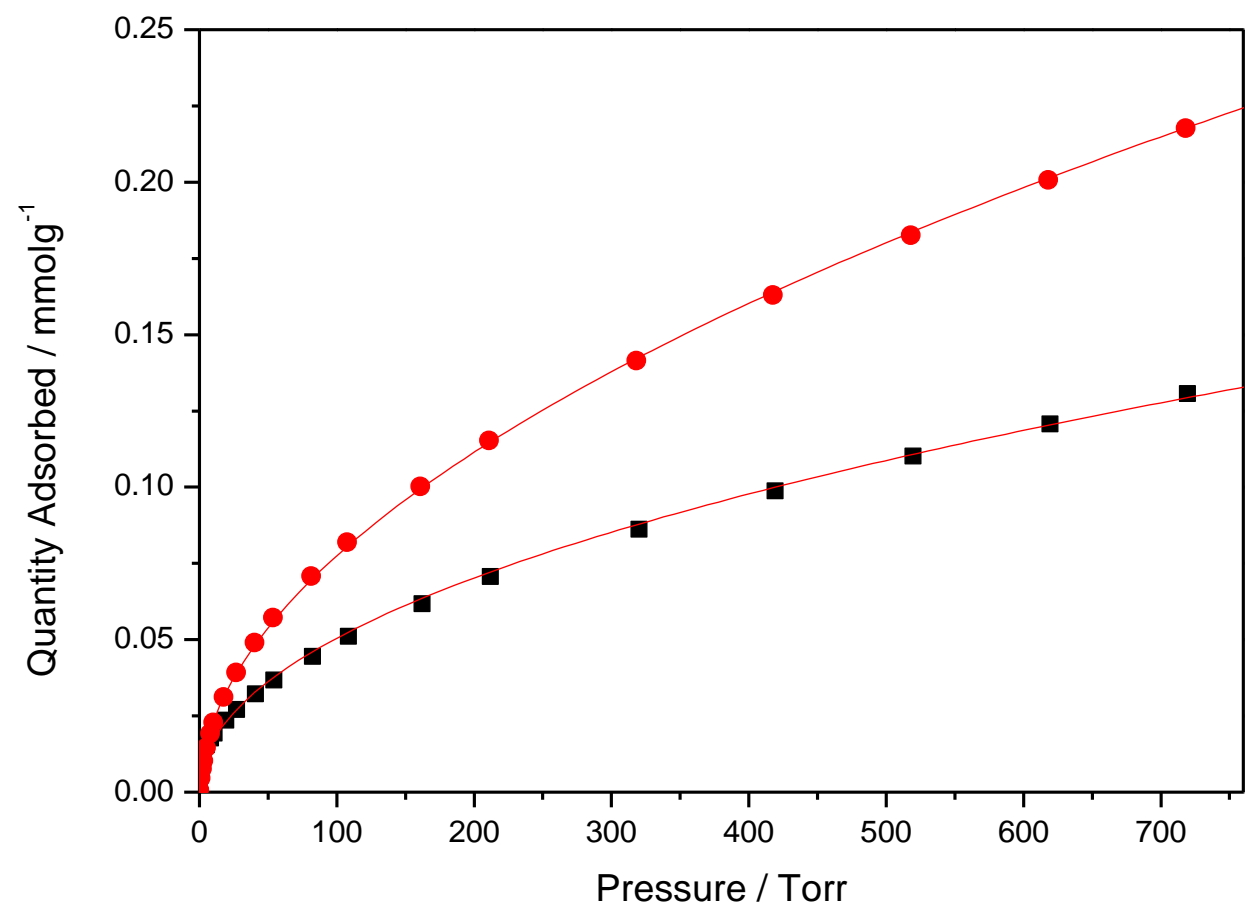

Figure $5-\mathrm{CO}_{2}$ adsorption isotherms $\left(T=35^{\circ} \mathrm{C}\right)$ for $\mathrm{Na}-\mathrm{SiO}_{2}$ (black squares) and $\mathrm{Ca}-\mathrm{SiO}_{2}$ (red circles). Non-linear fitting of Freundlich isotherm model (red lines).

Table 2 - Freundlich isotherm fitting parameters with standard error and correlation coefficients obtained by non-linear fitting of $\mathrm{Na}-\mathrm{SiO}_{2}$ and $\mathrm{Ca}-\mathrm{SiO}_{2}$.

\begin{tabular}{|c|c|c|c|}
\hline & $\mathbf{K}_{\mathbf{f}}$ & $\mathbf{n}$ & Adjusted $\mathbf{R}^{2}$ \\
\hline $\mathrm{Na}-\mathrm{SiO}_{2}$ & $5.6 \times 10^{-3} \pm 0.3 \times 10^{-3}$ & $2.10 \pm 0.04$ & 0.9977 \\
\hline $\mathrm{Ca}-\mathrm{SiO}_{2}$ & $6.9 \times 10^{-3} \pm 0.1 \times 10^{-3}$ & $1.91 \pm 0.01$ & 0.9997 \\
\hline
\end{tabular}

Metal loading on the surface was determined (Table 3) by EDX and indicated that 2.11 and $1.04 \mathrm{mmol} \mathrm{g}^{-1}$ of $\mathrm{Na}$ and $\mathrm{Ca}$, respectively had been deposited on the surface. The determined loading values compare well with the original publication, albeit for $\mathrm{K}$, where a 
loading of $6.9 \mathrm{wt} \%$ was achieved at equilibrium. ${ }^{32}$ In another publication from our group using $\mathrm{K}$-exchanged $\mathrm{SiO}_{2}$ this loading was achieved precisely, offering confidence in the preparative technique and subsequent analysis. ${ }^{49}$ Cation-exchange was shown be at equilibrium due to the constant values attained in the $\mathrm{pH}$ measurement during synthesis. This would initially appear to be consistent with an exchange of one hydroxyl group for each monovalent $\mathrm{Na}$ cation and two hydroxyl groups for each divalent $\mathrm{Ca}$ cation. Considering the concentration of surface hydroxyl groups on amorphous silica -4.6 and $4.9 \mathrm{OH} \mathrm{nm}-2$ (least squares and arithmetical mean) ${ }^{48}$ a metal coverage can be calculated (Supporting Information) based on the above cation-exchange assumptions, hydroxyl group concentration and cation loading (Table 3 ). Coverage $(\theta)$ is defined as the amount of adsorption sites $(\mathrm{OH})$ occupied by adsorbate ions $(\mathrm{Na} / \mathrm{Ca})$, expressed as a percentage of available surface sites based on the concentrations for amorphous silica above. ${ }^{48}$ In both cases coverage was found to be close to one monolayer, with a range presented in Table 3 when considering the two values for hydroxyl group concentration. Even though this calculation would infer that all available hydroxyl groups have been consumed during the cation-exchange procedure, FTIR showed (Figure 2) that in the doped samples free isolated hydroxyl groups existed. It is reasonable to explain this observation on the basis that the referenced hydroxyl group concentrations underestimate the true value. However based on experimental observations, it would appear that three dimensional oxide-like phases were also present on the silica surface, either terminated with free hydroxyl groups or leaving silanols exposed on uncovered silica surface.

When considering the $\mathrm{CO}_{2}$ uptake at the conditions of the FTIR experiments (15 Torr), the $\mathrm{CO}_{2}$ uptake calculated using the fitting parameters was 0.02 and $0.03 \mathrm{mmol} \mathrm{g}^{-1}$ for $\mathrm{Na}$ $\mathrm{SiO}_{2}$ and $\mathrm{Ca}-\mathrm{SiO}_{2}$, respectively. Comparing this to the metal loading observed in the EDX 
experiments (Table 3), it could be that during the early stages of adsorption, where FTIR indicates that chemisorbed carbonates form, the $\mathrm{CO}_{2}$ uptake can be rationalised considering ionic charge. As a free carbonate anion would require twice as many $\mathrm{Na}^{+}$ cations for charge balance, and there is roughly twice as much $\mathrm{Na}\left(2.11 \mathrm{mmol} \mathrm{g}{ }^{-1}\right)$ present compared to $\mathrm{Ca}\left(1.04 \mathrm{mmol} \mathrm{g}^{-1}\right)$, the similar low pressure uptake values can be explained on the basis of charge balance. At increasing pressure the uptake values diverge owing to the differences in the surface area of the materials as shown by the identical area normalised values (Figure 5). Initial adsorption formed chemisorbed carbonates, with subsequent adsorption related to layers atop the initial carbonates or from the growth of a three-dimensional phase. A maximum uptake of $\mathrm{CO}_{2}$ as related to the metal loading was not achieved, which was related to the nature of the isotherm.

Table 3 - Metal loading as determined by EDX expressed as total wt\% of the sample and as molar cation loading. Values are presented as an average of multiple points with standard deviation. Coverage $(\theta)$, the amount of adsorption sites $(\mathrm{OH})$ occupied by adsorbate ions $(\mathrm{Na} / \mathrm{Ca})$ is shown as determined assuming 4.9 and $4.6 \mathrm{OH} \mathrm{nm}^{-2}$ for the lower and upper bounds respectively (Supporting Information).

\begin{tabular}{|c|c|c|c|}
\hline & cation loading / & cation loading / & coverage $(\boldsymbol{\theta}) / \%$ \\
$\mathbf{m m o l ~ g}^{-1}$ & & \\
\hline $\mathrm{Na}-\mathrm{SiO}_{2}$ & $4.85 \pm 0.24$ & 2.11 & $102.9-109.6$ \\
\hline $\mathrm{Ca}-\mathrm{SiO}_{2}$ & $4.16 \pm 0.05$ & 1.04 & $101.2-107.9$ \\
\hline
\end{tabular}




\section{Conclusions}

To understand rate determining processes occurring during carbon storage it is necessary to understand speciation and the formation of ligands known to enhance dissolution in silicate minerals. Furthermore the sensitivity of such ligands or carbonate minerals formed during storage to the presence or absence of water is relevant to both long term geological storage and direct air capture where moisture is unavoidable.

Using our motif based system, the ability to adsorb and react with gaseous $\mathrm{CO}_{2}$ to form surface carbonates has shown that at the fundamental level, carbonates show dependence not only on cation and the presence of water, but on the order in which they are exposed to moisture and with time. These results have implications for the nature of carbonates formed during carbon storage over timescales where brine moves through a reservoir and modifies the speciation. Modelling requires realistic input for dissolution rates and the presence of ligands known to enhance dissolution are of interest.

The characterisation of the materials showed that the main change to the parent material was the reduction of the surface area which subsequently impacted the $\mathrm{CO}_{2}$ uptake at higher pressures. At the pressures encountered in geological formations this effect will have even greater precedence. The onset of crystallisation induced by the presence of a cation has been shown previously and was confirmed.

Hydrophilicity of the amorphous silica material was shown to decrease and increase upon doping with $\mathrm{Na}$ and $\mathrm{Ca}$ respectively, indicating that nanoscale changes to the surface could have impacts on wettability and plume migration on the macroscale.

By placing the cation on the surface it was possible to determine carbonate coordination and the effect of impurities, such as water, in a reasonable timescale for laboratory study. 
The complex nature of carbonate coordination when considering different reactive cations and the sequence of exposure of $\mathrm{CO}_{2}$ and water was elucidated.

Finally the difference in pressure between the present study and realistic process conditions are a limitation in the interpretation of results. However, previous work from our group with a potassium system, relevant to K-feldspar dissolution and soluble carbonate formation, at reservoir pressure and temperature conditions, indicated that the effect of pressure was negligible on the speciation, at least in the initial stages of carbonate coordination considered within. ${ }^{49}$

Overall a process to prepare materials permitting the study of carbonate formation at the individual cation level has been presented. These results have implications for wettability changes and carbonation reactions during mineralisation of $\mathrm{CO}_{2}$ in subsurface storage locations. Importantly it was shown that the presence of water, known to have implications in various capture materials, oxide looping cycles and carbon storage, directly impacts the speciation of carbonates formed. These results have wider implications for catalysis, biomineralisation, utilisation of $\mathrm{CO}_{2}$ and systems where the initial stages of carbonate formation are significant.

\section{Supporting Information}

$\mathrm{N}_{2}$ adsorption-desorption isotherms, pore size distribution plots for as prepared and calcined samples, and coverage calculations. 


\section{Acknowledgement}

A Doctoral Training Grant (EP/K0502960/1) for G.A.M. from the Engineering and Physical Sciences Research Council (EPSRC) is gratefully acknowledged. The Erasmus programme is thanked for supporting a study visit for R.W. to Turin.

\section{References}

1. Keeling, C. D.; Whorf, T. P., A compendium of data on global change, atmospheric carbon dioxide records from sites in the sio air sampling network, T. A. Boden, D. P. Kaiser, R. J. Sepanski, F. W. Stoss Eds.; 1994.

Oak Ridge National Laboratory, U.S. Department of Energy, Oak Ridge, Tenn., U.S.A. doi: 10.3334/CDIAC/atg.035

2. International Energy Agency. Redrawing the energy-climate map. World energy outlook special report, 2013.

3. Tans, P.; Keeling, R., Trends in atmospheric carbon dioxide. Global greenhouse gas reference network, 2014.

Tans P, Keeling R (2014) Global Greenhouse Gas Reference Network - Trends in Atmospheric Carbon Dioxide. NOAA/ESRL. Available: http://www.esrl.noaa.gov/gmd/ccgg/trends/global.html

4. Olajire, A. A., $\mathrm{CO}_{2}$ capture and separation technologies for end-of-pipe applications - A review, Energy 2010, 35, 2610-2628.

5. Keeling, C. D.; Whorf, T. P.; Wahlen, M.; Van der Plichtt, J., Interannual extremes in the rate of rise of atmospheric carbon dioxide since 1980, Nature 1995, 375, 666670. 
6. Olajire, A. A., A review of mineral carbonation technology in sequestration of $\mathrm{CO}_{2}, \mathrm{~J}$. Petroleum Sci. Eng. 2013, 109, 364-392.

7. Hicks, J.C.; Drese, J.H.; Fauth, D.J.; Gray, M.L.; Qi G.; Jones, C.W., Designing adsorbents for $\mathrm{CO}_{2}$ capture from flue gas - hyperbranched aminosilicas capable of capturing $\mathrm{CO}_{2}$ reversibly, JACS 2008, 130, 2902-2903.

8. Blamey, J.; Anthony, E.J.; Wang J.; Fennell, P.S., The calcium looping cycle for large-scale $\mathrm{CO}_{2}$ capture, Progress in Energy and Combustion Science 2010, 36, 260-279.

9. Kumar, A.; Madden, D.G.; Lusi, M.; Chen, K.; Daniels, E.; Curtin, T.; Perry J.J.; Zaworotko, M.J., Direct air capture of $\mathrm{CO}_{2}$ by physisorbent materials, Angew. Chem. Int. Ed. 2015, 54, 14372-14377.

10. Shi, X.; Xiao, H.; Lackner K.S.; Chen X., Capture $\mathrm{CO}_{2}$ from ambient air using nano confined ion hydration, Angew. Chem. Int. Ed. 2016, 55, 4026-4029.

11. Boot-Handford, M. E.; Abanades, J. C.; Anthony, E. J.; Blunt, M. J.; Brandani, S.; MacDowell, N.; Fernandez, J. R .; Ferrari, M. C.; Gross, R.; Hallett, J. P. et al, Carbon capture and storage update, Energy \& Environ. Sci. 2014, 7, 130-189.

12. Benson, S.M.; Cole D.R., $\mathrm{CO}_{2}$ sequestration in deep sedimentary formations, Elements 2008, 4, 325-331.

13. Tong, D.; Martin Trusler J.P.; Vega-Maza D., Solubility of $\mathrm{CO}_{2}$ in aqueous solutions of $\mathrm{CaCl}_{2}$ or $\mathrm{MgCl}_{2}$ and in a synthetic formation brine at temperatures up to $423 \mathrm{~K}$ and pressures up to $40 \mathrm{MPa}$, J. Chem. Engin. Data 2013, 58, 2116-2124

14. Burnside N.M.; Naylor M., Review and implications of relative permeability of CO2/brine systems and residual trapping of $\mathrm{CO} 2$, Int. J. Greenhouse Gas Control 2014, 23, $1-11$. 
15. Zevenhoven, R.; Fagerlund J.; Songok J.K., $\mathrm{CO}_{2}$ mineral sequestration: developments toward large-scale application, Greenhouse Gases Sci. Tech. 2011, $1,48-57$.

16. Druckenmiller M.; Maroto-Valer M. M., Carbon sequestration using brine of adjusted pH to form mineral carbonates, Fuel Proc. Tech. 2005, 86, 1599-1614.

17. Zevenhoven R.; Fagerlund, J., Carbon Dioxide as Chemical Feedstock, Aresta, M., Ed.; Wiley VCH Verlag, Germany, 2010.

18. Seifritz, W., $\mathrm{CO}_{2}$ disposal by means of silicates, Nature 1990, 345, 486.

19. Zevenhoven, R.; Fagerlund J.; Songok, J. K., $\mathrm{CO}_{2}$ mineral sequestration: developments toward large-scale application, Greenhouse Gas Sci. and Tech. 2011, 1, 48-57.

20. Sanna, A.; Uibu, M.; Caramanna, G.; Kuusik, R.; Maroto-Valer, M. M., A review of mineral carbonation technologies to sequester $\mathrm{CO}_{2}$, Chem. Soc. Rev. 2014, 43, 8049-8080.

21. Robie, R. A.; Hemingway, B. S.; Fischer, J. R., Thermodynamic properties of minerals and related substances at $298.15 \mathrm{~K}$ and 1 Bar (105 Pascals) pressure and at higher temperatures, US Geolog. Bull. 1978, 1452. 
22. Dunsmore, H. E., A geological perspective on global warming and the possibility of carbon dioxide removal as calcium carbonate mineral, Ener. Conv. and Manag. 1992, 33, 565-572.

23. Lackner, K. S.; Wendt, C. H.; Butt, D. P.; Joyce, E. L.; Sharp, D. H., Carbon dioxide disposal in carbonate minerals, Energy 1995, 20, 1153-1170.

24. Wildenborg, T.; Chadwick, A.; Deflandre, J. P.; Eiken, O.; Mathieson, A.; Metcalfe, R.; Hattenberger, C. S.; Wollenweber, J., Key messages from active $\mathrm{CO}_{2}$ storage sites, Ener. Proc. 2013, 37, 6317-6325.

25. Sanna, A.; Uibu, M.; Caramanna, G.; Kuusik R.; Maroto-Valer, M.M., A review of mineral carbonation technologies to sequester $\mathrm{CO}_{2}$, Chem. Soc. Rev. 2014, 43, 8049-8080.

26. Berg A.; Banwart, S.A., Carbon dioxide mediated dissolution of Ca-feldspar: implications for silicate weathering, Chem. Geol. 2000, 163, 25-42.

27. Lu, P.; Fu, Q.; Seyfried, W. E.; Hedges, S. W.; Soong, Y.; Jones, K.; Zhu, C., Coupled alkali feldspar dissolution and secondary mineral precipitation in batch systems - 2: New experiments with supercritical $\mathrm{CO}_{2}$ and implications for carbon sequestration, Appl. Geochem. 2013, 30, 75-90.

28. Brady P. V.; Walther, J. V., Controls on silicate dissolution rates in neutral and basic pH solutions at $25^{\circ} \mathrm{C}$, Geochim. Cosmochim. Acta 1989, 53, 2823-2830.

29. Plettinck, S.; Chou, L.; Wollast, R., Kinetics and mechanisms of dissolution of silica at room temperature and pressure, Mineral. Mag. 1994, 58A, 728-729.

30. Wijnen, P. W. J. G.; Beelen, T. P. M.; De Haan, J. W.; Van De Ven, L. J. M.; Van Santen, R. A., The structure directing effect of cations in aqueous silicate solutions. A ${ }^{29}$ Si-NMR study, Colloids and Surfaces 1990, 45, 255-268. 
31. Rimstidt, J. D., Rate equations for sodium catalyzed quartz dissolution, Geochim. Cosmochim. Acta 2015, 167, 195-204.

32. Iordan, A.; Kappenstein, C.; Colnay, E.; Zaki, M. I., Surface contribution to the interfacial chemistry of potassium modified oxide catalysts. Silica-alumina versus silica and alumina, J. Chem. Soc. Faraday Trans. 1994, 94, 1149-1156.

33. Sing, K. S. W., Reporting physisorption data for gas/solid systems with special reference to the determination of surface area and porosity, Pure \& Appl. Chem. $1982,54,2201-2218$.

34. Grosman, A.; Ortega, C., Capillary condensation in porous materials. hysteresis and interaction mechanism without pore blocking/percolation process, Langmuir 2008, 24, 3977- 3986.

35. Lu, P.; Hsieh, Y., Highly pure amorphous silica nano-disks from rice straw, Powder Tech. 2012, 225, 149-155.

36. Kumagai, S.; Sasaki, J., Carbon/silica composite fabricated from rice husk by means of binderless hot-pressing, Bioresource Tech. 2009, 100, 3308-3315.

37. Abdel-Mohdy, F. A.; Abdel-Halim, E. S.; Abu-Ayana Y. M.; El-Sawy, S. M., Rice straw as a new resource for some beneficial uses, Carbohydrate Polymers 2009, 75, 44-51.

38. Morrow, B. A.; McFarban, J. J., Surface vibrational modes of silanol groups on silica, J. Phys. Chem. 1992, 96, 1395-1400. 
39. Farokhpoor, R.; Bjørkvik, B. J. A.; Lindeberg, E.; Torsaeter, O., $\mathrm{CO}_{2}$ wettability behavior during $\mathrm{CO}_{2}$ sequestration in saline aquifer - An experimental study on minerals representing sandstone and carbonate, Energy Proc. 2013, 37, 53395351.

40. Busca, G.; Lorenzelli, V., Infrared spectroscopic identification of species arising from reactive adsorption of carbon oxide on metal oxide surfaces, Mat. Chem. 1982, 7, 89-126.

41. Lavalley, J. C., Infrared spectrometric studies of the surface basicity of metal oxides and zeolites using adsorbed probe molecules, Catal. Today 1996, 27, 377-401.

42. Bal, R.; Tope, B. B.; Das, T. K.; Hegde, S. G.; Sivasanker, S., Alkali-loaded silica, a solid base: investigation by FTIR spectroscopy of adsorbed $\mathrm{CO}_{2}$ and its catalytic activity, J. Catal. 2001, 204, 358-363.

43. Fukuda, Y.; Tanabe, K., Infrared study of carbon dioxide adsorbed on magnesium and calcium oxides, Bull. Chem. Soc. Japan. 1973, 46, 1616-1619.

44. Chu, C. C.; Sheppard, N., Proc. XVth EUCMOS, Norwich. (1981)

45. Morandi, S.; Prinetto, F.; Castoldi, L.; Lietti, L.; Forzatti, P.; Ghiotti, G., Effect of water and ammonia on surface species formed during NOx storage-reduction cycles over $\mathrm{Pt}-\mathrm{K} / \mathrm{Al}_{2} \mathrm{O}_{3}$ and $\mathrm{Pt}-\mathrm{Ba} / \mathrm{Al}_{2} \mathrm{O}_{3}$ catalysts, $P C C P$ 2013, 15, $13409-13417$.

46. Sarzanini, C.; Sacchero, G.; Pinna, F.; Signoretto, M.; Cerrato, G.; Morterra, C., On the amount and nature of sulfates at the surface of sulfate-doped zirconia catalysts, J. Mater. Chem. 1995, 5, 353-360.

47. Shi, X.; Xiao, H.; Lackner K.S.; Chen X., Capture $\mathrm{CO}_{2}$ from ambient air using nano confined ion hydration, Angew. Chem. Int. Ed. 2016, 55, 4026-4029. 
48. Zhuravlev, L.T., The surface chemistry of amorphous silica. Zhuravlev model, Colloids Surface A 2000, 173, 1-38.

49. Mutch, G. A.; Anderson, J. A.; Walker, R. E.; Cerrato, G.; Morandi, S.; Operti L.; Vega-Maza, D., In-situ FTIR spectroscopy as a non-invasive technique to study carbon sequestration at high pressure and high temperature, Int. J. Greenh. Gas Control 2016, 51, 126-135.

\section{Table of contents}

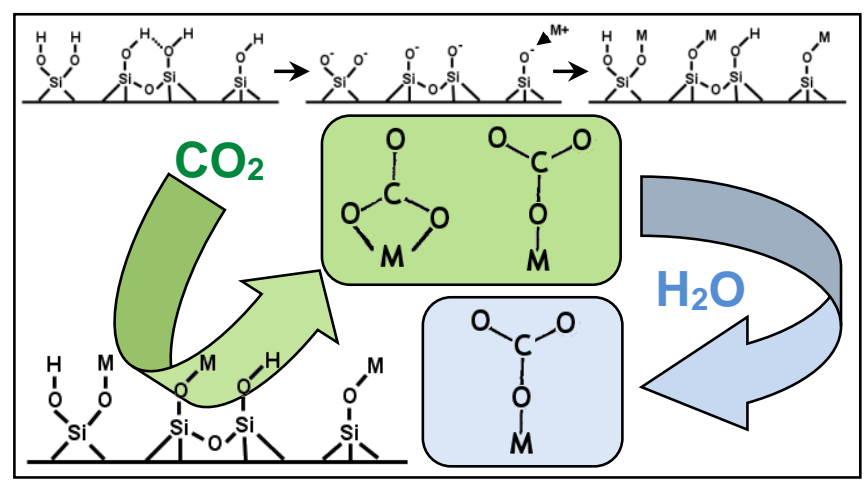

